\title{
The Voices of Male Nurses in Kerala: Career Choice and Satisfaction
}

\author{
Cinoj George ${ }^{+*}$ and Dr Feyza Arman Bhatti ${ }^{i}$
}

\section{Abstract}

There are more male nurses than ever before in India. While there is a large number of studies that focus on the differences in working conditions between male and female nurses and perceptions towards male nurses in western contexts, these studies are almost non-existent in highly patriarchal contexts like India. Utilising twenty semi-structured interviews with male nurses in three cities of Kerala, geospatially located in South India, this research aims at exploring the reasons why male nurses select the profession and their gendered experiences during their career paths. The research argues that male nurses select the profession for increasing their chances to migrate to industrialised countries like Australia and the United Kingdom. However, they face various social and work-related impediments in their career, which include negative perceptions of families and others towards the profession, the discrimination faced in terms of occupational segregation at the workplace, negative perceptions towards their manhood and the difficulties in finding a bride. Male nurses, if unsuccessful in migrating abroad, are not committed to remaining in the profession, particularly after their "shelf-lives" are over. In this case, they are highly likely to move to other professions or migrate to second-option countries in the Middle East. This emerges as a concern for India which is in dire need of nurses and highlights that Indian and State governments need to take prompt actions that would eliminate the stereotypes concerning male nurses, improve the working conditions and reduce discrimination towards male nurses, and in general to include more men in mainstream nursing.

Keywords: Male Nurses, Career Choice, Satisfaction, Semi-Structured Interviews, Kerala, India

\footnotetext{
${ }^{\dagger}$ Research Scholar, Department of Business and Economics, Girne American University, Turkish Republic of Northern Cyprus

${ }^{*}$ Corresponding Author, Email: cinojgeorge@live.com

ì Assistant Professor, Department of Business and Economics, Girne American University, Turkish Republic of Northern Cyprus, Email:feyzabhatti@gau.edu.com

(C) 2019 George \& Bhatti. This is an Open Access article distributed under the terms of the Creative Commons Attribution License (http://creativecommons.org/licenses/by/2.0), which permits unrestricted use, distribution, and reproduction in any medium, provided the original work is properly cited.
} 


\section{Introduction}

Florence Nightingale's 19th Century 'feminisation of nursing' made nursing a femaleonly profession and the notion of 'female care' continue to linger in the minds of $21^{\text {st }}$-Century society. There is a prevalent belief among people at large that female nurses are ideal for offering special care for both sexes while it is reckoned as an unbecoming role for male nurses, such as inserting a catheter on a female patient (Harding, North \& Perkins, 2008). Florence Nightingale viewed men to be devoid of the ability to show empathy and provide patient care and viewed nursing primarily as a woman's profession. Nursing was perceived to be an extension of a woman's role at home, and she theorised nursing was unsuitable for men's hands as their rough hands were 'not fitted to touch, bathe and dress wounded limbs' (Brown, Nolan \& Crawford, 2000).

The effects of feminisation of nursing by Florence Nightingale continues to loom large on male nurses, although the perception is gradually fading with more men entering the profession; it would be long before male nurses are accepted and are shown inclusiveness by society at large. Despite increasing numbers of male nurses, it is only in a few countries where male nurses have entered the profession with a complete disregard for the social stigma that is associated with the choice of career. In most countries, Middle East and North Africa region in particular men have found it difficult to break the cultural barrier that persists. (Masters, 2009).

The struggles of men in a female-dominated industry are invariably different from the struggles of women in a male-dominated industry. In this context, it is arguable that the nursing experience of a male nurse would be incomparable from their female counterparts (O'Lynn, 2004). A large body of literature explores the differences in experiences of male and female nurses and indicate that the most significant impediment for a male nurse in his career is his gender itself. Different scholars have put forward their arguments in different ways.
For instances, Halloran \& Welton (1994) argued that the existing social mores have resulted in creating a barrier for men's success in nursing. Male nurses are generally ascribed one of the three roles by society, the trouble maker, the Heman and the homosexual. The trouble maker is the one who is assertive and aggressive at work, wherein the He-Man is the one who does all the carrying and heavy work and the homosexual is the one who is compassionate and shows empathy towards his patients (Evans, 1997).

There is occupational segregation in nursing, general nursing and patient care are assigned for female nurses, while male nurses are allocated nursing duties which demand physical strength. Male nurses have to defend their career choice by choosing nursing departments which are manlier and less feminine. Male nurses usually choose or are given psychiatric wards, intensive care units or operation theatres. Choice of the department is either voluntary or given depending on the existing social construct (Black, 2014).

Studies have also shown that male nurses are more likely to have more attrition from workplace than their female counterparts due to low work satisfaction. The constant need for clarifying their roles can be very unsettling for male nurses because acceptance positively impacts their job satisfaction or a lack thereof (Meadus \& Twomey, 2011). Many factors such as salary, lack of acceptance and satisfaction and limited career growth opportunities have been identified as the reason for men leaving nursing. Attrition at work is not limited to men quitting from their job roles, rather it is also abandoning their profession altogether. Scholars suggest that male nurses find it challenging to make a career out of nursing as most supervisory positions are given to female nurses (Andrews, Stewart, Morgan, \& D'Arey, 2012: Comber \& Barriball, 2007; Toh, Ang, \& Devi, 2012).

In India, in the last decade alone more men have joined the industry compared to the last 70 years since independence (Nair \& Healey, 2006). The number of male nurses in Kerala have nearly doubled from a mere $11 \%$ to $21 \%$ in a span of 5 
years between 2011 and 2016 (Official statistical information, 2016). In spite of many studies conducted globally, there has been a lack of research into addressing the choice of nursing as a career option among the male nurses and the level of satisfaction at work in an Indian context.

This research attempts to explore and identify the rationale and work experiences of male nurses in the cultural context of India and Kerala in particular through a qualitative study. So, for achieving the objective, the following issues among male nurses in Kerala were examined:

- The factors that influence 'Nursing' as a career choice.

- Perceptions of family members and society towards male nurses.

- Particularities of male nurses at workplace and beyond, including challenges in getting married and questions on manhood are revealed.

- Career ambitions and future plans are discussed.

\section{Nursing in India: A Background}

Nursing as a profession was alien to Indian society, and during pre-independent India, nurses were drawn mainly from Anglo-Indian or Christian communities (Raghavachari, 1990). The first training school for training nurses and mid-midwives was established in erstwhile Madras presidency in the late $18^{\text {th }}$ Century (Jaggi, 2001). The early nursing professionals were limited to the port cities and were widowed, deserted wives or in the worst case orphans who had no professional future in the patriarchal Indian society of the bygone era. (GOI, 1929).

Indeed, nursing as a profession was not socially accepted by Indian society as it was the role of the woman in a household to take care of the sick and elderly (Gill, 2014). When hospitals were established Indians were not willing to work as

\footnotetext{
${ }^{1}$ As per the Hindu holy scriptures, caste system is basically a way of segregating population into four social groups/hierarchies, with Brahmins (Priests and teachers) occupying the highest class, and Untouchables, also known as Harijans or Dalits, as casteless or outcastes.
}

nurses due to the prevailing caste system. ${ }^{1}$ Cleaning people or cleaning body fluids were deemed to be the work of the untouchables or the outcasts (Arnold, 1993). Since nursing involved touch and caring for strangers outside the household, nurses were viewed as vulnerable to prostitution by the general public. Such a perception created a natural barrier for the general public to accept this profession due to which nursing students preferred a career in teaching rather than work as a nurse (Noordyk, 1921).

The colonial approach of educating and employing downtrodden women of the Indian society culminated in a feminised and submissive workforce which was comprised of only women. After independence nursing education was at par with western standards of health care and continues to do so. However, Nursing was and still is incompatible with public health needs of Indian society (Walton-Roberts, 2012).

Since independence, Kerala has been the largest source of nurses in India and for Indian nurses abroad. Women in Kerala had the opportunity for education long before it was available in the other parts of the country. During the colonial and post-colonial era, there were a significant number of schools that exclusively catered to girl's education. Schooling and literacy rate combined with the substantial Christian population the paved way for women in Kerala to capitalise on the opportunity to become trained nurses as it served both their spiritual and professional needs (Abraham, 2004).

Women from Kerala found nursing as the most suitable profession. They perceived nursing as a career choice that provides them with ample job opportunities both in India and abroad. Female nurses from Kerala found nursing to be of an advantage as this is one of the few industries where women do not have any direct competition in their professional sphere from

Kshatriyas (warriors and rulers), Vaisyas (farmers, merchants, and artisans), and Sudras (laborers) are the remaining three castes (Subedi, 2013). 
the other gender. Nursing is a preferred career choice among women in Kerala in general and Christian women in particular (Nair, 2007).

However, a common problem that is rampant in Indian hospitals is the systematic ill-treatment of nurses by doctors and society in general. Nurses are treated as helpers or as subordinates by the doctors. A senior nurse in most cases is better equipped and knowledgeable than a junior doctor who is a recent graduate. Instead of cooperation, there seems to be a feudal attitude towards nurses (Nair \& Healey, 2006). The economic superiority of doctors has resulted in the marginalisation of nurses; they have become voiceless or have been silenced by the hospital management. A rise in a nurse's income jeopardises the hegemony of doctors which can shatter the established professional and gender hierarchy (Oommen, 1978; Thomas, 2006).

In another study by (Boughn, 2001) reveals that both male and female nurses have similar reasons in joining the nursing profession. It argued that both male and female nurses chose to nurse to provide care for others, but men were more vocal about problems at the workplace which ranged from salary to working environment. This study found that male nurse indeed for stability at work.

Similarly, (La Rocco, 2007) identified a trajectory of four linear stages that encompass the path men travel to become nurses. They are:

- Choosing to nurse as a profession

- Becoming a nurse

- Being a nurse

It is noted that men working in large cities have greater acceptance as opposed to male nurses working in rural areas of a country. The experiences of male nurses also vary depending on factors like the area of specialisation. Literature shows that men working in operation theatres, emergency or any critical care wards showed a greater sense of work satisfaction than nurses working in non-critical areas (Evans, 1997).

In light of the aforementioned arguments, the objective of this research is to identify why men choose to nurse as a career option and how is it to work as a nurse? The study aims to look into the personal and professional lives of men in nursing in Kerala. Since the entry of male nurses into the workforce is a recent phenomenon and India is a patriarchal society, there is a need to explore the lived experience of the male nurses to understand the societal attitude towards them (Jinks \& Bradley, 2004).

The next section is a brief description of qualitative research design and methodology deployed in this research. Following this, it critically discusses the factors driving the men into the nursing profession using their lived experiences.

\section{Research Design and Methodology}

As stated above, this research employs a qualitative approach utilising data collected during a PhD research study conducted in Kerala in 2018.

The data was collected through 20 face to face semi-structured interviews, which lasted for an hour on an average. The interviews were conducted in the state of Kerala between June and August 2018. The researcher chose three of the biggest cities in Kerala (Kochi, Calicut and Trivandrum) as most of the hospitals are concentrated in these cities. In each city, the participants were selected using snowball sampling technique after accessing at least one male nurse from a private hospital. The author contacted the participants using references provided by their friends and asked for a convenient location for the interview.

The semi-structured interviews were conducted in the participant's house which was the choice of the participants. The interview was conducted in Malayalam thereby allowing the participants to express themselves without any inhibitions. Semi-structured interviews often attempt to study experiences of the participants (Flyvbjerg, 2006). Language expresses meaning and simultaneously influences how meaning is ascribed. People use words in their language to express their experiences, but sometimes the phrases and metaphors used in one language are different from the other (Polkinghorne, 2005). 
Some phrases in Malayalam is different, for instance, it is common to say (to go out) to refer to migrate to another country. Most of the participants use this phrase than use the word 'migrate' as there is no equivalent word/phrase fore 'migrate'. Interpretation in communication is paramount and cannot be overlooked. Interpretation may get tangled mainly when the cultural context differs. However, the author bearing excellent command in both languages (Malayalam and English) transcribed and translated the interviews for the analysis.

The ethical approval for the research was obtained from ethical committee of the University where the authors are working before the field visit. A participant information sheet with detailed information of the research was provided to the participants along with a written consent form. The participants were informed on the rationale of the study and that the data would be used only for academic purposes. They were allowed to ask questions about the research before to the interview and were informed of their right to withdraw from the research even after the interview was conducted (within six months). Participants were assured of anonymity, that is, the participants' name, role, and the name of the hospital where they worked would be concealed.

The interviews were recorded to have an accurate account and were transcribed and translated to English by the author. The transcripts were coded thematically using qualitative software (AtlasTi), and the themes were identified on the basis of the objective of the study. A list of the participants and their background information are provided in Table 1. All the names used in the study are pseudonyms.

\section{Research Findings}

During the interviews, the male nurses were asked about the reasons for selecting nursing as a career, the perception of their families and others about their career choice and what it means to be a male nurse in Kerala, India. The findings are provided below.

\section{The Reasons for Selecting Nursing as a Career}

When asked about their preference for nursing as a career, two themes emerged. One of the most common reasons for selecting nursing as a career was mentioned as 'going out' that is, to migrate or go abroad.

\section{Nursing as a Career: A Road to Migration}

The majority of the nurses said they chose this profession to find a job abroad and settle somewhere other than India. They considered nursing as a backdoor entry to European or other western countries. Australia and the UK emerged as their favourite destination due to easy migration policies and permanent resident status offered within a couple of years. Out of 20 participants 12 wanted to find jobs in the UK, and the rest in Australia and Ireland. Middle Eastern countries were also considered as an option, though as a secondary destination. As the participants commented:

I can say to a certain extent, I decided to become a nurse because I have more opportunities abroad than in India (Felix).

I decided to become a nurse because it was the easiest way to migrate. My dream since my schooldays was to migrate and nursing career is the best option. I want to migrate to the UK (Victor).

I think going abroad is the best thing to happen, most people made their money working abroad, in places like Dubai or America. If I work in Kerala I don't think I have a future... I mean as a male nurse, finding a job is very difficult and even if I do some other non-nursing job I wouldn't be able to make a lot of money. So either ways I won't have a successful life in Kerala. So I will try to go abroad, otherwise I will find some non-nursing job in the Middle East (Kenan). 


\begin{tabular}{|c|c|c|c|c|c|c|}
\hline Name & Age & Religion & Location & $\begin{array}{l}\text { Educational } \\
\text { Qualification }\end{array}$ & $\begin{array}{l}\text { Marital } \\
\text { Status }\end{array}$ & $\begin{array}{l}\text { Work } \\
\text { Experience }\end{array}$ \\
\hline Tamir & 32 & Muslim & Kochi & B.Sc. Nursing & Married & 8 Years \\
\hline Felix & 28 & Christian & Kochi & B.Sc. Nursing & Single & 5 Years \\
\hline Govind & 26 & Hindu & Kochi & B.Sc. Nursing & Single & 4 Years \\
\hline Dinto & 28 & Christian & Kochi & B.Sc. Nursing & Single & 6 Years \\
\hline Davis & 25 & Christian & Kochi & B.Sc. Nursing & Single & 3 Years \\
\hline Gokul & 26 & Hindu & Kochi & B.Sc. Nursing & Single & 4 Years \\
\hline Akhil & 29 & Hindu & Kochi & B.Sc. Nursing & Single & 7 Years \\
\hline Jijo & 29 & Christian & Kochi & B.Sc. Nursing & Single & 6 Years \\
\hline Christo & 27 & Christian & Kochi & B.Sc. Nursing & Single & 5 Years \\
\hline Jatin & 26 & Hindu & Kochi & B.Sc. Nursing & Single & 3 years \\
\hline Lal & 25 & Hindu & Kozhikode & B.Sc. Nursing & Single & 3 Years \\
\hline Shabir & 30 & Muslim & Kozhikode & B.Sc. Nursing & Married & 6 years \\
\hline Omesh & 34 & Hindu & Kozhikode & B.Sc. Nursing & Married & 13 Years \\
\hline Adi & 30 & Hindu & Kozhikode & B.Sc. Nursing & Single & 7 Years \\
\hline Riyas & 36 & Muslim & Kozhikode & B.Sc. Nursing & Married & 13 Years \\
\hline Savio & 25 & Christian & Trivandrum & B.Sc. Nursing & Single & 3 Years \\
\hline Michael & 31 & Christian & Trivandrum & B.Sc. Nursing & Married & 9 Years \\
\hline Victor & 29 & Christian & Trivandrum & B.Sc. Nursing & Single & 8 Years \\
\hline Yasir & 31 & Muslim & Trivandrum & B.Sc. Nursing & Single & 10 Years \\
\hline Kenan & 27 & Christian & Trivandrum & B.Sc. Nursing & Single & 4 Years \\
\hline
\end{tabular}

Seven of the male nurses mentioned that they do not want to come back to India even if the salaries were higher. The reasons for migration although seemed primarily due to financial conditions and better quality of life abroad, most of the male nurses also voiced their concerns about the prevailing working conditions in Kerala, and better ones abroad. Humiliation and having no respect towards nursing in Kerala was one of the reasons mentioned frequently during the interviews. As Govind mentioned:

UK is where I want to be, because in India there is no respect for nurses. It is a better place to work, and we have better quality of life along with better salary. I have few of my friends there, and they are all very happy. UK has many opportunities for Indians especially for nurses in Kerala. Every day you can see a lot of advertisement calling for nurses to work in the UK. I guess most nurses in Kerala become nurses with the intention to migrate (Govind).

Similarly, Davis commented:

There should be a proper support system and appreciation at work. We are part of medical profession, we don't deserve 
this humiliating treatment. I want to work in Australia, it gives PR [permanent residency] in 3 years (Davis).

The working hours, conditions and attitudes towards male nurses were also considered as better in western countries. As Jijo, Lal and Omesh said their nurse friends were happy in their work, their friends, did not face discrimination on the basis of gender. In addition, they had better working standards and work-life balance.

My future plan is to migrate to Ireland. I will not get any good job here in India or in the Middle East. So, Ireland is the best shot. European countries do not differentiate on gender and the work hours are really good there. I became a nurse so that I can settle abroad (Jijo).

My dream hospital is in the UK. I have my friends who work there, and they are happy (Lal).

I want to migrate to the UK, because they have better working standards and I have friends who say that work-life balance is great. I do not want to work in India anymore (Omesh).

\section{Nursing as an Alternate Profession}

Another typical pattern that emerged during the interviews was the preference for nursing as a career after an unsuccessful stint in another profession.

I am 26 years old, and I did nursing after my B.Com because I could not find any job. I was planning to do some master's degree, but I was not sure. My mom suggested me to become a nurse. She is a nurse, and she said that I have much potential to grow in this profession. Nurses are in high demand in India and abroad. So I thought of becoming one (Gokul).

I did my business degree, and I chose nursing as my second career because nursing is the best option to migrate, and people told me there is no future in doing a business degree. I thought it is better to be a professional and you always see advertisements in paper calling nurses for Ireland and UK. I thought I will finish my degree and migrate (Adi).

\section{Perceptions of Family and Others}

Nursing is perceived as not being a suitable profession for a man; the experiences of male nurses in Kerala about how they received treatment by their families and friends were mainly negative. However, there was a greater support from those families, who considered nursing as a profession to migrate and thereby enhance the economic standards of the families. Nonetheless, the majority of them complained about the difficulties in convincing their families or being ridiculed by their friends.

The majority of the nurses interviewed had at least a family member who was a nurse. They, however, often found themselves at odds with their friends and family because of their career choice. It was noticed that nobody received any encouragement or support from their family when they first mentioned about their decision to become a nurse with the exception of one nurse who received full support from his family as his family found nursing as a profession that could enable their son's chances to migrate abroad and make money.

In fact my mother was my inspiration and in some ways she forced me to be a nurse. She wanted me to go abroad and make money. She always wanted to go out of country but she could not so now she wants me to do that (Christo).

Most of the participants had to implore and convince their parents to send them to nursing school. When asked about how people perceived their career choice, Felix said:

Oh! It was difficult. I had a tough time convincing my family that I want to be a nurse. My parents were completely against my decision especially my father. They still are... Sometimes I avoid going to social gathering. I end up being a joke. They do not know how important nursing is. It is just attitude. They are not willing to change the age-old beliefs that nurses 
have to be female. A friend of mine asked me whether I am gay. They think it is effeminate to be a nurse. It took me one year to convince my family my requests fell on deaf ears (Felix).

Indeed, the majority of these male nurses were advised to take up any profession in the medical field apart from nursing, which would seem more suitable for men. As Shabir and Jatin lamented:

I think nursing has much potential. I wanted to be a physiotherapist, but I changed my mind and decided to become a nurse. If you look at job advertisements in the newspaper every day you have ads for nurses to work abroad. It is not ok to be a nurse, but it is ok to be a lab technician or a physiotherapist (Shabir).

My friends laughed at me when I told them I want to be a nurse. My brother told me to do pharmacy instead of nursing (Jatin).

\section{Being a Nurse in Kerala: Problems at and Beyond the Workplace}

Stereotyping and marginalisation were common for all the nurses, male nurses felt they had to defend their career choice all the time. Some felt that the attitude of public towards male nurses make them feel stressed as they always have to defend their career choice. These male nurses found it difficult to perform their duties because of the constant taunts either direct or indirect from their patients. While Savio commented on the demands for the female nurses, Yasir said he retorts when patients question him:

We have patients who demand female nurses. They often accuse us of being harsh and rude to them. Most of the time, its prejudice that speaks. I do not know why they say that it is a misconception. Nobody wants a male nurse in patient care (Savio).

So most male nurses end up being heavy lifters or pushers. We have to push the stretcher etc... this attitude confines to lifting, critical care or emergency duties. Even patients ask for female nurses and then I tell them a nurse is a nurse gender does not matter (Yasir).

Another problem that the majority of the nurses faced was acceptance in society. The findings revealed that all the participants had lied about their job at least once to public. They feel embarrassed to tell people about their job. As Dinto and Adi said:

I just tell people I work in the hospital. Otherwise I have to tell them that I am a male nurse and I fear that I might get embarrassed (Dinto).

If a woman enters a male-dominated profession, it is appreciated. If it is us entering a female-dominated profession we have no respect. I have to lie to people sometimes about my job. I once told a girl that I was a surgeon (Adi).

An experienced nurse is more knowledgeable than a junior doctor. I have told people that I am a doctor sometimes to old patients too because they keep pestering me with questions if I tell them that I am a nurse (Michael).

This clearly shows that nurses are uncomfortable talking about their jobs. Male nurses feel compelled to lie about their job to be socially accepted. These findings indeed bear resonance to previous research (Cross, 2002; Simpson, 2004).

\section{Questioned Manhood}

The research finding further unveiled that the majority of the nurses were saddened by the lack of support due to the perceived lack of manliness in the job. Six male nurses felt that their manliness was either questioned or they were seen as predators. Felix, as above, already shown mentioned that male nurses were perceived as gay, and some others perceived male nurses to be sexual predators. As Savio narrated:

Also people are fine with male doctors, but they are not comfortable with male nurses. It is funny that male nurses are 
asked to leave gynaecology wards, but the same people are OK with a male doctor as if only male nurses are perverts (Savio).

\section{Finding a Bride}

One of the most surprising aspects of the finding was that the majority of the male nurses expressed their dissatisfaction in finding bridges. Indeed, marriage emerged as another problem for male nurses. Some nurses found it difficult to get married, at least in India even with a female nurse.

They were of the opinion that female nurses do not want to marry male nurses and parents of women from a non-nursing background had similar ideas about male nurses. As Victor, Akhil, Lal and Kenan stated:

Now when I reflect why my father was right in discouraging me; it is very challenging to find a bride for male nurses because nobody wants to marry a male nurse (Victor).

Nobody wants to marry a male nurse. Even a female nurse does not want to marry a male nurse. I am stuck here. I am trying to move to the UK. If I do not get through I will stop being a nurse and go to Dubai or do a master's in business or something like that. I do not see the future. I ruined my future. I also spent a lot on my studies (Akhil).

After all, people read about us in the newspaper, and they know about our working conditions. If a male nurse works abroad, it is easy to find a bride. Otherwise even marriage is difficult is for us (Lal).

I want to change the attitude that people have towards us, you see even female nurses don't want to marry a male nurse. When a man marries a nurse people say it is because we want to migrate with them. So we find it difficult to marry someone from our same profession (Kenan).
Indeed, in all cases, the participants reported. That no one should go through such a harrowing process to become a nurse. Overall finding demonstrated that being a male nurse, they have to struggle on multiple fronts, at work, in the society, to find a spouse and above all the sword of shelf-life hanging over their heads. Most nurses believe they cannot continue in the profession for a longer period due to the lack of career growth and hiring limitations due to their gender. At the same time, the majority had their back-up plans should they wish to (dis)continue their nursing profession. This was reflected in the narratives of Tamir, Govind and Felix:

I want to work in the UK; they need many nurses. If I cannot migrate I will go to Dubai and do some marketing job (Tamir).

Most men quit nursing after some time as they get fed up due to work stress or because of salary. I love my job and I do not want to quit it. I have spent my money and time into this profession. I cannot just walk away. Male nurses usually quit after 10 or 12 years (Govind).

Hospitals want less staff and more work. That is the hospital strategy to make money. We question it, so we become the target. Who will hire a male nurse who is bald and 35 years old? There was a boom in the number of men entering nursing colleges when I did my nursing. Now the trend has completely reversed nobody wants to be a male nurse any more. Male nurses are a dying breed I presume (Felix).

\section{Discussion and Conclusion}

The principal aim of this research is the examination of the lived experiences of male nurses of Kerala. The findings support the findings from previous studies conducted in nonIndian contexts (Cross, 2002; Simpson, 2004; Twomey \& Meadus, 2016). Nursing still remains a profession that is unwelcome to men though some inroads by male nurses have been made (Duffin, 2006). The idea that nursing is a female profession by and large remains in public 
perception and has not waned. All male nurses interviewed cited experiences of gender stereotyping and discrimination in hospitals across Kerala. Male nurses believed that barriers exist for men to enter and survive in this profession. This observation validates previous research by O'Lynn, (2004) and Stott (2007). It was found that entering the profession as a male nurse is easier than surviving as a male nurse.

Male nurses choose this profession due to the pull factor of migrating abroad, since Kerala has many migrant female nurses abroad. Men believed nursing could provide them with the same opportunities that were available for women. Many participants and their families view nursing as a passport to western or developed countries. And interestingly, none of the participants' showed interest in pursuing a nursing career in India. Nonetheless, these participants felt the need to change their career if they were unsuccessful in securing a job abroad.

However, the participants believed that their career choice is antithetical to society because of which they feel discriminated against.

This study found out that there are cases where men are seen as abnormal in choosing nursing as a career due to the prevalent gender stereotypes and perceptions that exist in a patriarchal society. There is a need for de-feminised nursing to include more men. Men were seen less masculine or homosexuals if they were nurses which makes it difficult for men to disclose about their job to strangers in their social life.

The findings further suggest that there is a need for substantial restructuring of attitudes and practices at both workplace and society to make nursing an inclusive profession for both genders. Male nurses can offer considerable contributions to Indian health workforce, which is highly understaffed. Right education and awareness can help in attracting and retaining more talent in nursing.

While this study was conducted amongst only 20 participants in the state of Kerala, it has lays the groundwork for future research and can be replicated in other states of the country.

\section{References}

Abraham, B. (2004). Women nurses and the notion of their 'empowerment'. Discussion Paper No. 88. Thiruvananthapuram, Kerala, India: Centre for Development Studies.

Andrews, M. E., Stewart, N. J., Morgan, D. G., \& D'Arcy, C. (2012). More alike than different: A comparison of male and female RNs in rural and remote Canada. Journal of Nursing Management, 20, 561-570.

Arnold, D. (1993). Colonizing the body: State medicine and epidemic disease in nineteenthcentury India. London: University of California Press.

Black, P. M. (2014). Professional nursing: concepts \& challenges, 7th edition. Missouri: Elsevier.

Boughn, S. (2001). Why women and men choose nursing. Nursing and Health Care Perspectives, 22(1), 14-19.

Brown, B., Nolan, P., \& Crawford, P. (2000). Men in nursing, ambivalence in care, gender and masculinity. International History Nursing Journal, 5(3), 4-13.

Coomber, B., \& Barriball, K. L. (2007). Impact of job satisfaction components on intent to leave and turnover for hospital-based nurses: A review of the research literature. International Journal of Nursing Studies, 44, 297-314.

Cross, S. (2002). 'Girls' jobs for the boys: Men in non-traditional occupations'. Gender, Work and Organization, 9(2), 204-226.

Duffin, C. (2006). Lack of training in intimate care adds to male nurses' isolation. Nursing Standard, 20(52), 10.

Evans, J.A. (1997). Men in nursing: Issues of gender, segregation and hidden advantage. Journal of Advanced Nursing, 26(2), 226-231.

Flyvberg, B. (2006). Five misunderstandings about case study research. Qualitative Inquiry, 12 (2), 219-245.

Gill, R. (2014). International migration of skilled health workers: A case study of Indian nurses. 
Unpublished Doctoral Thesis, Jawaharlal Nehru University.

GOI [Government of India]. (1929). Triennial report on the working of the civil hospitals and dispensaries in the Madras Presidency for the years 1926, 1927 and 1928. Madras: Superintendent, Government of India, Government Press.

Halloran, E. J., \& Welton, J. M. (1994). Why aren't there more men in nursing? In J. McCloskey, $\mathrm{H}$. Grace (Eds.) Current issues in nursing, 4th ed. Mosby-Year Book, St Louis; 1994.

Harding, T., North, N., \& Perkins, R. (2008). Sexualizing men's touch: male nurses and the use of intimate touch in clinical practice. Research and Theory for Nursing Practice, 22(2), 88-102.

Jaggi, O. P. (2001). Nursing profession in India. In O. P. Jaggi, \& D. Chattopadhyaya (eds), Medicine in India: Modern Period History of Science, Philosophy and Culture in Indian Civilization (Vols. IX, part 1, pp. 203-212). New Delhi: PHISPC Centre for Studies in Civilization.

Jinks, A.M., \& Bradley, E. (2004). Angel, handmaiden, battle-axe or whore? A study which examines changes in newly recruited student nurses' attitudes to gender and nursing stereotypes. Nurse Education Today, 24(2), 121-127.

LaRocco, S. A. (2007). A grounded theory study of socializing men into nursing. Journal of Men's Studies, 15(2), 120-129.

Masters, K. (2009). Role development in professional nursing practice (2nd ed), London: Jones and Bartlett.

Meadus, R. J., \& Twomey, J. (2011). Men student nurses: The nursing education experience, Nursing Forum, (4), 269-273. http://onlinelibrary.wiley.com/doi/10.1111/j .1744-6198.2011.00239.x/epdf.

Meadus, R. J., \& Twomey, J. (2016). Men nurses in Atlantic Canada: Career choice, barriers, and satisfaction. Journal of Men's Studies, 24(1), 78-88.
Nair, S. (2007). Rethinking Citizenship, Community and Rights: The Case of Nurses from Kerala in Delhi. Indian Journal of Gender Studies, 14(1), 137-156.

Nair, S., \& Healey, M. (2006). A Profession on the Margins: Status Issues in Indian Nursing. Delhi: CWDS.

Noordyk, W. (1921). Nursing in India. The American Journal of Nursing, 21(5), 28-40.

O’Lynn, C. E. (2004). Gender based barriers for male students in nursing education. Journal of Nurse Education, 43(5), 229-236. http://www.ncbi.nlm.nih.gov/pubmed/1515 2800.

Official statistical information. (2016, 3 March). Retrieved on 15 June 2019 from, http:// https://mohfw.gov.in/documents/staistics

Oommen, T. K. (1978). Doctors and nurses. Delhi: Macmillon Company of India.

Polkinghorne, D. (2005). Language and meaning: data collection in qualitative research. Journal of Counselling Psychology, $52,137-145$.

Raghavachari, R. (1990). Conflicts and adjustments: Indian nurses in an urban milieu. Delhi: Academic Foundation.

Simpson, R. (2004). Masculinity at work: The experiences of men in female dominated occupations. Work, Employment and Society, 18(2), 349-68.

Stott, A. (2007). Exploring factors affecting attrition of male students from an undergraduate nursing course: A qualitative study. Nurse Education Today, 27(4), 325332.

Subedi, M. (2013). Some theoretical considerations on caste. Dhaulagiri Journal of Sociology and Anthropology, 7, 51-54.

Thomas, P. (2006). International migration of Indian nurses. International Nursing Review, 53(4), 277-283.

Toh, S. G., Ang, E., \& Devi, M. K. (2012). Systematic review on the relationship between the nursing shortage and job 
satisfaction, stress, and burnout levels among nurses in oncology/ haematology settings. International Journal of Evidence-Based Healthcare, 10, 126-141.
Walton-Roberts, M. (2012). Contextualizing the global nursing care chain: International migration and the status of nursing in Kerala, India. Global Networks, 12(2), 175-194. 